\title{
Editorial
}

\author{
Melania Cornish, Alan Critchley, Anicia Hurtado, Danilo Largo, Nicholas Paul \\ and Leonel Pereira
}

\section{Seaweed resources of the world: a 2020 vision. Part 3}

https://doi.org/10.1515/bot-2019-0093

As the world prepares to live the year 2020, this series of special issues published by Botanica Marina, highlighting world seaweed resources has, indeed, proven to be rich fodder for visionaries. Its production and publication coincide with a time when social justice movements across the world have become united around global environmental issues and climate change. Increasing concerns over $\mathrm{CO}_{2}$ levels and warming temperatures are now front and center, and we are watching the effects manifest in our local weather events. The youth have found a collective voice and they are demanding action, and while we are all responsible, it is those with power, the governments and influencers, who are held most accountable.

An update regarding the current status of the global Sustainable Development Goals put forward in 2015 by the United Nations was presented by the UN SecretaryGeneral, António Guterres (WHO 2019). He stated that: "It is abundantly clear that a much deeper, faster, and more ambitious response is needed to unleash the social and economic transformation needed to achieve our 2030 goals." One of the key findings of this report indicated that in 2018, the fourth warmest year on record, ocean acidity was $26 \%$ higher than in pre-industrial times, and at current emission rates, it is expected to increase by $100-150 \%$ by 2100 . Also, sadly, global hunger is on the rise - after a prolonged decline.

One's initial impulse after reading this report was perhaps to jump up and down and proclaim: "but seaweeds can help!”, and while it is widely demonstrated that there are multiple ways in which they indeed can and do, the general global populace is still some distance from realizing such important connections (ones which are patently obvious to the world's phycological community). Not surprisingly, the 2020 compilation of Seaweed resources of the world serves as an excellent guide, capable of laying out some of the groundwork (and what amounts to blindly obvious opportunities) for innovative solutions required and at hand, if implemented, to help tackle the Sustainable Development Goals. The title itself is descriptive: Seaweed resources of the world: a 2020 vision. How, one might ask, can this polyphyletic rag-bag of marine photosynthetic organisms provide for future generations of the planet? This informative series covers most of the definitions associated with the word "resource", including economics, ecology, presence/ absence, the management (or mis-management) of, and opportunities (grasped and ignored) and applications for the benefits of mankind, for as long as it matters. In somber consideration of a Doomsday scenario, mankind has been on this earth but a short time, and things will continue long after we leave it behind. Should the human race ultimately extinguish itself, the seaweeds - or at least some forms of algae - will remain intact and thriving on earth, as they did before our arrival. Perhaps if we let them, they will contribute to our survival.

Readers will find an example of rural, but extensive seaweed cultivation efforts in The seaweed resources of the Philippines (Trono and Largo 2019), for example, and there are mentions of various scale-size operations throughout this series. The presence, and in some cases, recent absences, of various seaweed resources are carefully documented for many locations across the globe.

Perhaps one can envision the future where consumers have access to region-specific seaweeds of value, drawing agricultural parallels to, for example, oranges from Valencia, or black truffles from France. Remember though, not all seaweeds are the same and much work is required in the realms of selection and domestication, and as with land plants, not all seaweed candidates will easily lend themselves to phyconomic production. However, this situation could add to their gastronomic and/or bioactivity value in terms of supply and demand. Examples of seaweeds of interest might be the flavorful Osmundea pinnatifida, or "pepper dulse", also sometimes called the "truffle of the sea" found seasonally around Ireland, or in the warmer water Caulerpa lentellifera, sea grapes which are highlighted as a tasty salad ingredient among the seaweed resources of Japan (Tanaka et al., this issue). Will these one day become trade items and available to consumers in other climates? Perhaps it would be wise to review the 
Editorial for Part 2 for business development comments, and of course, these are not simple ideas. This is the essence of phyconomy, the development of strains and cultivars of selected seaweeds and the methods required to produce them in industrial quantities by various methods both in the sea and in tanks on land, as highlighted by Craigie et al. (2019) in Commercialization of Irish moss aquaculture: the Canadian experience.

....and fundamentally, we need to continue to educate.

We believe Part 3 of Seaweed resources of the world: a 2020 vision lives up to the standards of the previous two issues. In this third issue readers can look forward to an overview by Barbier et al. of the European Project PEGASUS with guidelines for sustainable aquaculture of seaweeds - exciting times ahead! Access to and sustainable harvest from natural beds of seaweeds will always be a necessary component of providing the industrial quantities of some seaweeds required for processing. Understanding the standing stock through accurate measurements in space and time has always been a necessary requirement prior to allocation of sustainable exploitation harvesting quotas. Webster et al. provide a research article on just what new technologies are available and how they can be applied using an example of the intertidal fucoid Ascophyllum nodosum in eastern Canada. Part 3 continues with updates of resources and how they are being managed and utilized in a number of global regions. Tanaka et al. give an account for Japan which is instructive in terms of some of the present day challenges the seaweed industry there faces. Weinberger et al. and Michalak deals with northern Europe and Poland with a common coast of the Baltic Sea. The developments on the Israeli shores in the Eastern Mediterranean are brought up to date by Israel et al. Moving into tropical waters Mollion provides us with an account of the seaweed resources and utilization of Madagascar. Finally still in tropical waters Stiger and Zubia provide a very optimistic outline of the seaweed resources of French Overseas Territories with considerable detail on research undertaken to valorize these resources. This information is an excellent blueprint for what other regions of the globe might do to study and make sustainable, beneficial uses of their macroalgal resources.

Indeed, bringing these rich sources of information to phycologists is like preaching to the converted, the message has to be taken more broadly and widely across all levels of consumers and food manufacturers globally. There is a steady buzz of excitement resonating with commercially-minded phycologists, and this must be effectively conveyed to other scientists, industry players, and those who work with, or study seaweeds, taxonomically and ecologically. It would seem that in every climatic region of the marine world there exists at least one Sustainable Development Goal that carefully selected seaweeds could be customized to help meet the present and future needs of people and planet. Not necessarily a simple matter, but the positive aspects of seaweeds far outweigh any negatives, in a world where that balance is already quite shaky, and every positive contribution counts.

In consideration of the culture today, it appears that the Western World may never fully embrace seaweeds as a nutritious and versatile food. Never, however, is a very, very long time and should such a situation occur, it would enable marine macroalgae and their applications to become mainstream and more readily available to consumers.

There definitely remains much to do, indeed, as clearly pointed out in the Editorial to Part 1 of this series. With the consolidation and publishing of Part 3, the penultimate in this series of Seaweed resources, we can see that much has already been done. What of the next two decades? We look forward to the 2040 special issues when we hope to read that much of the potential has become a practical reality. A reality spurred on by the new entrants and the undoubtedly splendid progress of the next generation of phyconomic practitioners. By then, the various contributions, present and future, of seaweeds to the Sustainable Development Goals will be impossible to ignore. There are already food production models to demonstrate what works, and to learn from previous mistakes. Cultivation and production efforts for seaweeds in many ways parallel agriculture, and we now know what some of the pitfalls are when it comes to food production and the environmental "un"sustainability of certain aspects of our massive agricultural footprint. According to the UN Secretary-General, however, global hunger is precariously on the rise again. With the appropriate management of our global seaweed resources, we have yet another chance, and we can, and must, be much more careful this time around. Our planet, and its residents, depend upon it.

\section{References}

Craigie, J.S., M.L. Cornish and L.E. Deveau. 2019. Commercialization of Irish moss aquaculture: the Canadian experience. Bot. Mar. 62: 411-432.

Trono Jr., G.C and D.B. Largo. 2019. The seaweed resources of the Philippines. Bot. Mar. 62: 483-498.

World Health Organization (WHO). 2019. The Sustainable Development Goals Progress Report. United Nations Sustainable Development. https://www.un.org/sustainabledevelopment/ progress-report/ (accessed: November 01, 2019). 
Corresponding author: Melania Cornish, The Dr James S. Craigie Centre, Acadian Seaplants Limited, Cornwallis Industrial Park, Cornwallis, Nova Scotia, Canada, e-mail:mlc@acadian.ca Alan Critchley: Verschuren Centre for Sustainability in Energy and Environment, Cape Breton University, Sydney, Nova Scotia, Canada, e-mail: alan.critchley2016@gmail.com

Anicia Hurtado: University of the Philippines Visayas, Miagao, Iloilo, Philippines; and Integrated Services for the Development of Aquaculture and Fisheries (ISDA) Inc. MacArthur Highway Tabuc Suba, Iloilo City 5000, Philippines,

e-mail: anicia.hurtado@gmail.com
Danilo Largo: Research, Development, Extension and Publications Office, 3rd Floor, Baumgartner Learning Resource Center, University of San Carlos - Talamban Campus, Talamban, Cebu City 6000, Philippines, e-mail: largodb2016@gmail.com

Nicholas Paul: School of Science and Engineering, University of the Sunshine Coast, Sippy Downs, Queensland 4556, Australia, e-mail:npaul@usc.edu.au Leonel Pereira: Marine and Environmental Sciences Centre (MARE), Department of Life Sciences, Faculty of Sciences and Technology, University of Coimbra, 3000-456 Coimbra, Portugal, e-mail: leonel.pereira@uc.pt. https://orcid.org/0000-0002-6819-0619 